Revista de

Contabilidade e

Organizações
DOI: http://dx.doi.org/10.11606/rco.v8i22.58500
Journal of

Accounting and

Organizations

\title{
Características do comitê de auditoria e o gerenciamento de resultados: um estudo nas empresas listadas na BM\&FBOVESPA
}

\author{
Paulo Roberto da Cunhaa; Thifany Hillesheim ${ }^{\mathrm{b}}$; Dinorá Baldo de Faveri ${ }^{\mathrm{c}}$ Moacir Manoel Rodrigues Junior ${ }^{\mathrm{d}}$ \\ ${ }^{a}$ Universidade Regional de Blumenau \\ ${ }^{b}$ Universidade do Estado de Santa Catarina \\ c Universidade Federal de Santa Catarina \\ ${ }^{d}$ Universidade Regional de Blumenau
}

\section{Informações do Artigo}

Histórico do Artigo

Recebido: 12 de julho de 2013

Aceito: 12 de novembro de 2014

Palavras chave:

Comitê de Auditoria

Gerenciamento de Resultados

Governança Corporativa.

\begin{abstract}
Resumo
O estudo teve como objetivo verificar se características do Comitê de Auditoria refletem no Gerenciamento de Resultados (GR) das empresas brasileiras listadas na BM\&FBovespa. Foram analisadas 31 empresas em 2010 e 33 empresas no ano de 2011. A população corresponde as empresas listadas na BM\&FBovespa, totalizando 415 empresas. Foram excluídas as instituições financeiras e as empresas que não possuem Comitê de Auditoria, restando um total de 61 empresas. Desse total foram excluídas as empresas que não possuíam as características estudadas, tamanho, expertise e independência, e aquelas que não possuíam informações completas para o cálculo do gerenciamento de resultados pelo modelo Jones modificado, restando à amostra de 31 empresas em 2010 e 33 empresas em 2011. Os resultados apontam que a maior parte dos Comitês de Auditoria são compostos por até três membros e com até dois membros considerados independentes. No que tange a expertise constatou-se igual distribuição de frequência para empresas com um e dois membros formados na área contábil ou em áreas afins da área financeira, o que totaliza aproximadamente $50 \%$ das empresas. Na relação do GR e as características do comitê de auditoria, no ano 2010 constatou-se que apenas três variáveis, alavancagem, auditoria e setor contribuíam significativamente para o modelo inicial. Averiguou-se que apenas a variável alavancagem apresentou influência sobre a variável dependente. Já o ano 2011 demonstrou que nenhuma das variáveis independentes estudadas apresentou relação com a variável dependente denominada GR. Concluiu-se que nenhuma das características do Comitê de Auditoria estudadas apresentaram influência sobre o GR.
\end{abstract}

Copyright (C 2013 FEA-RP/USP. Todos os direitos reservados

\section{INTRODUÇÃO}

A Governança Corporativa nasce para superar o conflito da agência, que surge quando há separação entre propriedade e controle (VIANA, 2010). Pode ser considerada como um redutor da distância entre proprietários e administradores e a sociedade em geral. Siffert (1998) e Souza (2010) relatam que a Governança Corporativa passou a ter relevância com o surgimento das corporações modernas, pois tais organizações têm a segregação entre propriedade e controle como principal característica.

Desta forma a Governança Corporativa pode ser

Autor Correspondente: Tel + 5547 3321-0565

E-mail : pauloccsa@furb.br (P. R. Cunha); thifanyhillesheim@yahoo.com. br (T. Hillesheim); dinorabaldo@yahoo.com.br (D. B. Faveri); moacir_ro@ hotmail.com (M. M. R. Junior)

Universidade Regional de Blumenau. Rua Antônio da Veiga, 140

Victor Konder -89012900 - Blumenau, SC - Brasil considerada como um conjunto de mecanismos internos e externos pelo qual as organizações buscam alinhar os interesses do proprietário e do agente. Dentre os mecanismos internos destaca-se, por exemplo, a ação do Conselho de Administração, já como mecanismo externo tem-se como exemplo, a obrigatoriedade da publicação de informações sobre a companhia (SILVEIRA, 2002). O Conselho de Administração pode instituir vários comitês para auxiliá-lo na execução de suas atividades. Dentre os comitês que podem ser formados, há o Comitê de Auditoria, responsável por fiscalizar assuntos que envolvam demonstrações contábeis, controles internos, área financeira, auditoria interna e auditoria independente (IBGC, 2009a).

Embora se espere que, com a instituição do Comitê de Auditoria as organizações sejam mais transparentes sobre suas atividades, órgãos reguladores, governamentais e pesquisadores questionam a efetividade do trabalho do Comitê de Auditoria (FURUTA, 2010). Tal questionamento fundamenta-se nos escândalos ocorridos desde o ano 2000, envolvendo fraudes contábeis, 
originando a preocupação em relação ao efetivo monitoramento realizado pelo Comitê de Auditoria, visto que ele é responsável pela qualidade das demonstrações contábeis (TURLEY, ZAMAN, 2004).

Não há um conceito universal sobre o que é uma informação contábil de qualidade (COHEN, WRIGHT, KRISHNAMOORTHY, 2004), assim como não há uma métrica específica para medi-la. Dentre as formas utilizadas pelos pesquisadores para medir a qualidade das demonstrações contábeis está o gerenciamento de resultados (WANG, 2006; LOPES 2009). O conceito de Gerenciamento de Resultados está ligado a decisões tomadas por gestores de forma que beneficie mais um grupo de stakeholders do que outro, gerando assim forte assimetria de informação entre os diferentes usuários (SCHIPPER, 1989; MARTINEZ, 2001; CARDOSO, 2005, KLANN, 2011).

Diante do exposto, vale relacionar o Comitê de Auditoria com o gerenciamento de resultados, buscando respostas sobre a influência que o primeiro provoca no segundo, principalmente verificando as características da composição do comitê, visto que sua composição é um dos fatores que o torna eficaz ou não (BEASLEY, SALTERIO, 2001). Desta maneira admitiu-se por questão motivadora da pesquisa: Quais características do Comitê de Auditoria refletem no gerenciamento de resultados das empresas brasileiras listadas na BM\&FBovespa? Dado este questionamento, destaca-se como objetivo de pesquisa verificar se características do Comitê de Auditoria refletem no gerenciamento de resultados das empresas brasileiras listadas na BM\&FBovespa.

A relevância do tema pode ser definida sobre três aspectos: teórico, prático e social. Em relação ao aspecto teórico, este estudo pode ser considerado relevante e inédito, pois aborda o tema do gerenciamento de resultados em um período de implementação e consolidação das IFRS no Brasil conforme destaca Klann (2011), além de corroborar com pesquisas realizadas em países da Europa e Estados Unidos como Klein (2002), Bérdad et al. (2004), Krishnan (2005), Bronson et al. (2009), Kent (2010), Vlaminck e Sarens (2012), dentre outros. No âmbito prático, o presente estudo auxiliará o Conselho de Administração na composição do Comitê de Auditoria, visto que tal estudo busca conhecer as características necessárias que o comitê deve ter para que seja capaz de reduzir o gerenciamento de resultados e melhorar a qualidade das demonstrações contábeis da organização. Este conceito corrobora em importância com McDaniel et al. (2002), DeFond et al (2005) e Carcello et al. (2006) dentre outros trabalhos. Se tratando do aspecto social, pode-se considerar que, se encontrada a relação entre as características do Comitê de Auditoria e a qualidade das demonstrações contábeis, no que se refere ao gerenciamento de resultados, o estabelecimento dos membros do Comitê de Auditoria pode ser considerado uma decisão importante no que se refere à qualidade das demonstrações contábeis. Logo, os investidores terão mais respaldo ao utilizarem-se das informações contidas nas demonstrações contábeis das empresas que apresentam Comitê de Auditoria com as características destacadas neste estudo.

\section{FUNDAMENTAÇÃO TEÓRICA}

\subsection{Comitê de Auditoria como Instrumento de Governança Corporativa}

O Comitê de Auditoria é um mecanismo interno de Governança Corporativa, composto, preferencialmente, por membros do Conselho de Administração, que tem por responsabilidade supervisionar a gestão dos procedimentos internos, bem como assegurar que tais procedimentos sejam íntegros e eficazes para a produção de relatórios financeiros de qualidade, objetivando a proteção dos acionistas e demais usuários da informação contábil (IBGC, 2009b).

As atividades realizadas pelo Comitê de Auditoria têm por objetivo cuidar de ações específicas do Conselho de Administração. Estas ações correspondem a monitorar os controles internos e torná-los adequados, gerir riscos, gerar relatórios financeiros, atender as normas e leis, controlar e acompanhar a auditoria independente e a auditoria interna (SOUZA, 2010; CUNHA, 2011).

O Conselho de Administração deve estar seguro de que todos os componentes do Comitê de Auditoria sejam capazes de realizar as atividades atribuídas ao comitê (IBGC, 2009b). Souza (2010, p.29) destaca que "o desempenho das atividades do Comitê de Auditoria está intimamente relacionado à indicação de seus membros". Esta afirmação converge com Beasley e Salterio (2001), ao afirmarem que a composição do Comitê de Auditoria é um dos fatores que torna o comitê eficaz. Em virtude da possibilidade de ocorrer conflitos de interesses, recomenda-se que o Comitê de Auditoria seja composto pela maioria de membros independentes do Conselho de Administração (IBGC, 2009b).

Outro aspecto importante destacado para o comitê de Auditoria está ligado a evidências de que conselheiros do Comitê de Auditoria que exercem função ligada a este órgão em mais de uma empresa tendem a desempenhar seu papel com mais atenção, além de terem mais experiência. Yang e Krishman (2005), verificaram que os membros do comitê que possuem mais de um mandato ganham experiência, contribuindo na redução do gerenciamento de resultados. Vlaminck e Sarens (2012) verificaram uma relação positiva entre comitês com membros que possuem mais de três mandatos e a qualidade das demonstrações contábeis.

Destaca-se também como fator importante do Comitê de Auditoria é o seu tamanho. O IBGC não estabelece a quantidade de membros que o Comitê de Auditoria deve ter. Em estudos realizados anteriormente constatou-se que quanto maior o tamanho do Comitê de Auditoria, maior a variedade de conhecimentos existentes para o desempenho eficaz das atividades do comitê (YANG; KRISHNAN, 2005; KENT ET AL, 2010). 


\subsection{Qualidade da Informação Contábil e o Gerenciamento de Resultados}

Não há um conceito universal sobre o que é uma informação contábil de qualidade (COHEN; WRIGHT; KRISHNAMOORTHY, 2004). Paulo (2007) expõe que a qualidade da informação contábil pode ser entendida como um conjunto de características, como por exemplo, persistência, conservadorismo, gerenciamento de resultados, transparência, nível de disclosure, relação dos números contábeis com o desempenho dos preços das ações ou do valor de mercado da firma. O entendimento de qualidade das demonstrações contábeis para este estudo é caracterizado pela ausência de gerenciamento de resultados.

O gerenciamento de resultados advém dos julgamentos realizados pelos administradores sobre as informações financeiras e atividades operacionais, com o intuito de alterar as informações financeiras, ou iludir os investidores a respeito do desempenho econômico da companhia, ou ainda, influenciar nos resultados contratuais que dependam dos números informados pela contabilidade (HEALY; WAHLEN, 1999).

$\mathrm{O}$ gerenciamento de resultados refere-se às manipulações das informações contábeis realizadas pelos gestores com o intuito de obterem benefícios individuais, ou para que a organização demonstre uma situação econômica mais favorável a seus stakeholders (KLANN, 2011). A manipulação das informações contábeis distorce os objetivos para que as demonstrações contábeis sejam elaboradas: a tomada de decisões, visto que tal ação altera a realidade econômica e financeira da entidade (FUJI, 2004; GOULART, 2007).

Healy e Wahlen (1999) definem como três os motivos que incentivam o gerenciamento de resultados: vinculados ao mercado de capitais, incentivos contratuais e relacionados com a regulamentação. Martinez (2001) acrescenta ainda os custos políticos. Os motivos relacionados ao mercado de capitais referem-se ao incentivo que os gestores possuem em gerenciar os resultados devidos os investidores e analistas financeiros utilizarem da informação contábil para tomarem suas decisões referentes à compra de ações. Com o gerenciamento de resultados os gestores conseguem influenciar no curto prazo o desempenho das ações (HEALY; WAHLEN, 1999; MARTINEZ, 2001).

Segundo Paulo (2007), geralmente, considera-se informação contábil de baixa qualidade aquela que sofreu algum tipo de gerenciamento. Porém, há autores, como Jiraporn et al. (2008) que defendem que o gerenciamento de resultados pode trazer benefícios as empresas, pois devido à utilização de alguns princípios contábeis as informações ficam distorcidas, e não evidenciam a realidade econômica dos negócios.

O regime de competência define que as transações devem ser registradas no período de sua efetiva realização, onde as despesas são confrontadas com suas respectivas receitas, diferente do regime de caixa, que está focalizado nas entradas e saídas das disponibilidades. Verifica-se que o lucro líquido do período será diferente do fluxo de caixa líquido (MARTINEZ, 2001). Esta diferença existente é denominada como accruals (acumulações). As acumulações são todas as contas de resultado que entram no cálculo do lucro líquido, mas que não provocam alterações nas disponibilidades (MARTINEZ, 2008).

Martinez (2008) descreve que não há nada de errado em realizar o registro de accruals, o problema é que os gestores discricionariamente aumentam ou diminuem os accruals com o intuito de influenciar no lucro. O fato de o gestor conseguir acrescentar ou diminuir accruals faz com que estes sejam subdivididos em: accruals discricionários e accruals não discricionários.

Os accruals discricionários são uma proxy (medida) do gerenciamento de resultados (GOULART, 2007; MARTINEZ, 2008). Goulart (2007) descreve que a prática de gerenciamento de resultados fica mais forte $\mathrm{e}$ evidente quando os accruals discricionários são maiores. Se os accruals discricionários forem positivos, verificase que há interesse em aumentar o lucro ou melhorar o resultado. Caso os accruals discricionários forem negativos, constata-se o interesse de reduzir o lucro ou resultado.

Os modelos utilizados para medir o valor dos accruals discricionários variam dos mais simples aos mais sofisticados, tendo em vista separar os accruals discricionários dos não discricionários (MARTINEZ, 2008). Segundo Martinez (2008) não existe um modelo que seja perfeito. A Equação 1, retirada de Klann (2011, p. 78), mostra a maneira que o Modelo Jones Modificado estima os accruals discricionários.

$$
\begin{gathered}
T A_{i t}=\alpha_{i}+\beta_{1}\left[\Delta R E V_{i t}-\Delta R E C_{i t}\right]+\beta_{2} P P E_{i t}+\varepsilon_{i t} \\
\text { Equação 1 }
\end{gathered}
$$

Onde:

$\mathrm{TA}_{\mathrm{it}}=$ accruals totais da empresa i no ano t, calculadas pelo enfoque do Balanço;

$\triangle \mathrm{REV}=$ receita no ano $\mathrm{t}$ menos receita no ano $\mathrm{t}-1$ para a empresa i;

$\triangle \mathrm{REC}=$ são as contas líquidas a receber no ano $\mathrm{t}$ menos as contas líquidas a receber no ano t-1 para a empresa $\mathrm{i}$; $\mathrm{PPE}_{\mathrm{it}}=$ ativo imobilizado bruto no ano t para a empresa $\mathrm{i}$; $\varepsilon_{i t}=$ termo de erro no ano t para a empresa i (proxy de gerenciamento).

O estudo base, utilizado para a formulação do presente estudo, foi realizado por Vlaminck e Sarens (2012). Os autores estudaram as características do Comitê de Auditoria e o impacto provocado por elas na qualidade da informação contábil, utilizando como amostra empresas belgas. Devido basear-se em tal estudo, é que, assim como ele, utilizou-se o modelo Jones Modificado para medir o gerenciamento de resultados. 


\subsection{Construção das Hipóteses}

O IBGC não estabelece a quantidade de membros que o Comitê de Auditoria deve ter. Em estudos realizados anteriormente constatou-se que o tamanho do Comitê de Auditoria influencia na qualidade das demonstrações contábeis (YANG; KRISHNAN, 2005; KENT ET AL, 2010). Yang e Krishman (2005) estudaram a relação entre as características do Comitê de Auditoria e o gerenciamento de resultados trimestrais, constatando que um comitê menor pode ser mais funcional e supervisionar melhor os relatórios financeiros. Porém, um comitê maior terá uma maior variedade de conhecimentos, estando propenso a ter conselheiros independentes e com experiência empresarial e financeira, melhorando a qualidade das demonstrações contábeis.

Kent et al (2010) estudaram a relação entre estrutura de Governança Corporativa e a qualidade da informação contábil. Os autores verificaram, em uma amostra de 381 empresas australianas, que o tamanho do comitê está positivamente ligado a qualidade da informação contábil. Diante do exposto elabora-se a seguinte hipótese:

$\mathrm{H} 1=\mathrm{O}$ tamanho do Comitê de Auditoria está inversamente associado com o gerenciamento de resultados.

Para Beasley e Salterio (2001) a composição do Comitê de Auditoria é um dos fatores que torna o comitê eficaz. O Instituto Brasileiro de Governança Corporativa (IBGC), em seu Guia de Orientações para Melhores Práticas de Comitês de Auditoria (2009b) descreve que, o Conselho de Administração deve estar a todo o momento seguro de que os membros do Comitê de Auditoria sejam pessoas capazes e com qualidade suficiente para exercer suas funções de forma objetiva e independente. O IBGC (2009b) recomenda que o Comitê de Auditoria seja constituído preferencialmente por membros independentes.

Estudos realizados verificaram que, quanto maior o número de membros independentes que compõem o Comitê de Auditoria, menor será o gerenciamento de resultados, consequentemente melhor será a qualidade das demonstrações contábeis (ABBOTT; PARK; PARKER, 2000; KLEIN 2002; BÉDARD ET AL, 2004; KRISHNAN, 2005; BRONSON ET AL, 2009; KENT ET AL, 2010; VLAMINCK; SARENS, 2012).

Abbott, Park e Parker (2000) investigaram a relação entre a independência e atividade do Comitê de Auditoria, constatando que empresas que possuem comitês compostos por membros independentes têm menor probabilidade de serem atingidas por fraudes. Klein (2002) estudou a independência do Comitê de Auditoria em empresas norte-americanas, constatando relação negativa com o gerenciamento de resultados quando há um maior número de membros independentes na composição do comitê. Kent (2010) verificou, em empresas australianas, que quanto mais membros independentes comporem o Comitê de Auditoria, menor será a manipulação das demonstrações contábeis realizada pela gestão. Bérdad et al. (2004) e Bronson et al. (2009), constataram que o Comitê de Auditoria reduz o gerenciamento de resultados quando todos os membros do comitê são independentes, e não apenas a maioria. Vlaminck e Sarens (2012) realizaram seu estudo na Bélgica, buscando a relação entre as características do Comitê de Auditoria e a qualidade das demonstrações contábeis. Os autores encontraram uma relação positiva entre a independência do Comitê de Auditoria e a qualidade das demonstrações contábeis.

Percebe-se, dessa forma, que há uma relação positiva entre a independência dos membros do Comitê de Auditoria e a qualidade das informações contábeis, bem como uma relação negativa entre a independência dos membros e o gerenciamento de resultados. Dessa forma é estabelecida a seguinte hipótese:

$\mathrm{H} 2$ = A quantidade de membros independentes do Comitê de Auditoria está associada negativamente com o gerenciamento de resultados.

O IBGC (2009b) orienta que a maioria, ou pelo menos um dos membros do Comitê de Auditoria, seja qualificado nas áreas da Contabilidade, Auditoria e/ou Finanças. McDaniel et al. (2002), DeFond et al (2005) e Carcello et al (2006), verificaram em seus estudos que há uma relação negativa entre Comitês de Auditoria que possuem especialistas na área contábil, de auditoria e/ ou finanças e o gerenciamento de resultado, portanto há uma relação positiva com a qualidade das demonstrações contábeis.

McDaniel et al. (2002) estudaram os efeitos dos "alfabetizados financeiros" versus especialistas em finanças e contabilidade que compõem o Comitê de Auditoria, em relação a qualidade das demonstrações contábeis. Os resultados apontaram que os alfabetizados encontram facilmente os problemas relacionados às atividades empresariais, enquanto os especialistas em finanças e contabilidade identificam os problemas relacionados com a qualidade das demonstrações contábeis. DeFond et al. (2005) verificaram a reação do mercado quando são nomeados novos membros do Comitê de Auditoria, constatando que o mercado responde positivamente apenas quando os membros tem conhecimento em auditoria e especialidade contábil. Carcello et al. (2006) estudaram a experiência financeira e o conhecimento de gestão geral dos membros do Comitê de Auditoria e sua relação com o gerenciamento de resultados. Os autores constataram que a experiência financeira reduz o gerenciamento de resultados. Com base no exposto, formula-se a última hipótese da pesquisa:

$\mathrm{H} 3=\mathrm{O}$ número de experts em auditoria, contabilidade e/ou finanças na composição do Comitê de Auditoria está associada negativamente com o gerenciamento de resultados.

\section{MÉTODO E TÉCNICAS DA PESQUISA}

Com o intuito de construir e dar fundamento a pesquisa empírica, a fim de responder ao objetivo da 
pesquisa de verificar se as características do Comitê de Auditoria refletem no gerenciamento de resultados das empresas brasileiras listadas na BM\&FBovespa, esta sessão destina-se a descrever os métodos e procedimentos da pesquisa. Em um delineamento metodológico efetuado a luz de Gil (1999), Andrade (2010) e Richardson (2012) destaca-se esta como uma pesquisa descritiva quanto aos seus objetivos, documental quanto aos procedimentos e quantitativa quanto à abordagem.

Para a realização deste estudo utilizou-se como população as empresas listadas na BM\&FBovespa, totalizando 415 empresas. Dessas, foram excluídas as financeiras (devido às particularidades desse setor) e as empresas que não possuem Comitê de Auditoria, restando um total de 61 empresas. Desse total foram excluídas as empresas que não possuíam as características estudadas, tamanho, expertise e independência, e aquelas que não possuíam informações completas para o cálculo do gerenciamento de resultados pelo modelo Jones modificado, restando à amostra de 31 empresas em 2010 e 33 empresas em 2011.

A maior parte das empresas da amostra enquadra-se no Novo Mercado como nível de Governança Corporativa, totalizando 27 empresas. No Nível 2 tem-se 5 empresas e no Mercado Tradicional 2 empresas. Os setores que se destacaram foram: Construção e Transporte ( 8 empresas em 2010 e 9 empresas em 2011) e Consumo não cíclico (8 empresas em 2010 e 2011).

Para o teste das hipóteses usar-se-á um conjunto específico de variáveis voltadas para a descrição do comitê de auditoria. As variáveis utilizadas bem como a justificativa da utilização são apresentadas no Quadro 1.

Quadro 1. Constructo da pesquisa

\begin{tabular}{|c|l|l|}
\hline Variáveis & \multicolumn{1}{|c|}{ Operacionalização } & \multicolumn{1}{|c|}{ Autores } \\
\hline $\begin{array}{c}\text { Comitê de } \\
\text { Auditoria }\end{array}$ & $\begin{array}{l}\text { - A análise do Formulário de Referência das empresas, } \\
\text { verificando a informação da constituição do Comitê de } \\
\text { Auditoria }\end{array}$ & IBGC (2009b). \\
\hline Tamanho & $\begin{array}{l}\text { - Quantidade de conselheiros compondo o Comitê de } \\
\text { Auditoria }\end{array}$ & Yang e Krishnan, 2005; Kent et al, 2010. \\
\hline Independência & $\begin{array}{l}\text { - Quantidade de membros independentes no Comitê de } \\
\text { Auditoria }\end{array}$ & $\begin{array}{l}\text { Abbott, Park e Parker,2000; Klein, 2002; Bérdard et al, } \\
\text { 2004; Krishann, 2005; Bronson et al, 2009; IBGC, 2009b; } \\
\text { Kent et al, 2010; Vlaminck e Sarens, 2012. }\end{array}$ \\
\hline Expertise & $\begin{array}{l}\text { Auditoria } \\
\text { - Qualificação em áreas de contabilidade, auditoria e/ou } \\
\text { finanças } \\
\text { - Experiência anterior em contabilidade, finanças ou áreas } \\
\text { afins (Ex: economista e bancário) } \\
\text { - Certificação profissional em contabilidade }\end{array}$ & $\begin{array}{l}\text { Carcello et al, 2006; IBGC, 2009b; Cunha, 2011. } \\
\text { BRC, 1999; Mc Daniel et al, 2002; DeFond et al, 2005; }\end{array}$ \\
\hline $\begin{array}{c}\text { Accruals } \\
\text { discricionários }\end{array}$ & $\begin{array}{l}\text { Modelo Jones Modificado } \\
\text { Equação (1) }\end{array}$ & Martinez (2001); Klann (2011). \\
\hline
\end{tabular}

Fonte: Elaborado pelos autores.

O modelo para a verificação das hipóteses está descrito na Figura 1, esta mostra a construção das variáveis bem como seu conceito.

$|\mathrm{GR}|=\beta_{0}+\beta_{1}$ TamCA $+\beta_{2} \operatorname{Exp}+\beta_{3}$ Ind $+\beta_{4} \ln (\mathrm{AT})+\beta_{5}$ Alav $+\beta 6 \mathrm{CV}+\beta_{7}$ Int $+\beta_{8}$ Aud $+\beta_{9}$ ConcCAP $+\beta_{10}$ Setor

Onde:

Equação 2

Variável Dependente

$\mathrm{GR}=$ (Variável Dependente) Valor absoluto do gerenciamento de resultados

Variáveis independentes relacionadas ao Comitê de Auditoria:

TamCA = Tamanho do Comitê de Auditoria;

Exp $=$ Expertise dos membros do Comitê de Auditoria;

Ind = Independência dos membros do Comitê de Auditoria;
Variáveis independentes utilizadas como variáveis de controle:

$\ln (\mathrm{AT})=$ valor do ativo total em logaritmo natural;

Alav $($ Alavancagem $)=$ total do passivo dividido pelo total do patrimônio líquido no final do exercício;

$\mathrm{CV}($ Crescimento das vendas $)=$ percentual de mudança nas vendas líquidas;

Int (Internacionalização) = variável dummy, 1 para empresas com ações negociadas em bolsa de valores norte-americanas, e zero para outras;

Aud = variável dummy, sendo 1 para empresa auditada por PwC, KPMG, E\&Y ou D\&T, e zero para outras;

ConcCap $($ Concentração de capital $)$ = variável dummy, 1 caso o principal acionista da empresa detivesse menos de $50 \%$ das ações com direito a voto na empresa, e 0 caso o principal acionista detivesse $50 \%$ ou mais das ações com direito a voto na empresa.

Setor $=$ setor de enquadramento $(1=$ bens industriais, 2 = construção e transporte, $3=$ consumo cíclico, $4=$ consumo não cíclico, $6=$ materiais básicos, $7=$ tecnologia 
da informação e $8=$ utilidade pública)

Os dados referentes às características dos Comitês de Auditoria das empresas listadas na amostra da pesquisa, foram retirados do Formulário de Referência publicado pelas empresas nos anos de 2010 e 2011 no sítio da BM\&FBovespa, além de terem sido retiradas informações do próprio sítio das empresas, devido algumas informações não estarem no Formulário de Referência publicado na BM\&FBovespa. Os dados utilizados na apuração dos accruals discricionários foram coletados por meio da base de dados da economática ${ }^{\circledR}$, bem como os dados referentes às variáveis tamanho da empresa, alavancagem e crescimento das vendas. A coleta de dados realizou-se nos meses de outubro e novembro de 2012 .

Conforme Cunha e Coelho (2007, p. 133), "quando o problema apresentado tem por objetivo prever uma variável dependente a partir do conhecimento de mais de uma variável independente, a técnica estatística é denominada de regressão linear". Utilizou-se o método backward com a intenção de encontrar as variáveis dependentes que contribuíam significativamente para o modelo, reformulando, se preciso a equação inicial. Para a verificação de existência de relação entre a variável dependente e as independentes é preciso que as variáveis independentes do modelo apresentem significância estatística. Também foram verificados os principais pressupostos das regressões.

\section{DESCRIÇÃO E ANÁLISE DOS RESULTADOS}

Este seção destina-se a descrever e responder as hipóteses da pesquisa formuladas de acordo com o embasamento teórico. Inicialmente são apresentadas as características que destacam o Tamanho, o Número de Membros Independentes e a Expertise dos membros do comitê de Auditoria. Na segunda parte do processo de análise, são efetuados os testes deda regressão linear múltipla de modo a confirmar ou refutar as hipóteses de pesquisa.

\subsection{Características dos Comitês de Auditoria}

Como descrito anteriormente, as características observadas neste estudo referem-se ao tamanho do comitê (quantidade de membros), quantidade de membros independentes e quantidade de membros com expertise. A seguir são evidenciados os dados coletados sobre tais características.

A Tabela 1 refere-se ao tamanho do Comitê de Auditoria das empresas da amostra do ano de 2010.

Tabela 1. Tamanho dos Comitês de Auditoria

\begin{tabular}{c|c|c|c|c|c|c|c|c}
\hline \multirow{2}{*}{$\begin{array}{c}\text { Quantidade de } \\
\text { membros }\end{array}$} & \multicolumn{2}{|c|}{ Nível 2 } & \multicolumn{2}{c|}{ Novo Mercado } & \multicolumn{2}{c}{ Tradicional } & \multicolumn{2}{c}{ Total } \\
\cline { 2 - 9 } & $\mathbf{2 0 1 0}$ & $\mathbf{2 0 1 1}$ & $\mathbf{2 0 1 0}$ & $\mathbf{2 0 1 1}$ & $\mathbf{2 0 1 0}$ & $\mathbf{2 0 1 1}$ & $\mathbf{2 0 1 0}$ & $\mathbf{2 0 1 1}$ \\
\hline 1 a 3 & $3(9,7)$ & $4(12,1)$ & $21(67,7)$ & $18(54,5)$ & $1(3,2)$ & $1(3,0)$ & $25(80,6)$ & $24(72,7)$ \\
\hline 4 a 6 & $1(3,2)$ & $1(3,1)$ & $4(12,9)$ & $7(21,2)$ & $1(3,2)$ & $1(3,0)$ & $6(19,4)$ & $8(24,2)$ \\
\hline 7 a 9 & 0 & 0 & 0 & $1(3,1)$ & 0 & 0 & 0 & $1(3,1)$ \\
\hline Total & $\mathbf{4 ( 1 2 , 9 )}$ & $\mathbf{5 ( 1 5 , 2 )}$ & $\mathbf{2 5 ( 8 0 , 6 )}$ & $\mathbf{2 6 ( 7 8 , 8 )}$ & $\mathbf{2 ( 6 , 5 )}$ & $\mathbf{2 ( 6 , 0 )}$ & $\mathbf{3 1 ( 1 0 0 , 0 )}$ & $\mathbf{3 3 ( 1 0 0 , 0 )}$ \\
\hline
\end{tabular}

Fonte: Dados da pesquisa.

Observa-se na Tabela1 que a quantidade de membros que constituíam os comitês em 2010 variou de 1 a 6 membros, enquanto que em 2011 uma das empresas do novo mercado possuiu entre 7 e 9 membros. A maioria composta por um, dois ou três membros, somando um total de 25 empresas em 2010 e 24 em 2011, 80,6\% e 72,7\%, respectivamente, do total analisado. Os comitês compostos por quatro, cinco ou seis membros em 2011, representaram $24,2 \%$, com um total de oito empresas, sendo sete do Novo Mercado.

Outra característica verificada é a independência dos membros, a Tabela 2 apresenta a descrição da distribuição destes membros independentes.

Tabela 2 . Quantidade de membros independentes

\begin{tabular}{|c|c|c|c|c|c|c|c|c|}
\hline \multirow{2}{*}{$\begin{array}{l}\text { Quantidade de } \\
\text { membros }\end{array}$} & \multicolumn{2}{|c|}{ Nível 2} & \multicolumn{2}{|c|}{ Novo Mercado } & \multicolumn{2}{|c|}{ Tradicional } & \multicolumn{2}{|c|}{ Total } \\
\hline & 2010 & 2011 & 2010 & 2011 & 2010 & 2011 & 2010 & 2011 \\
\hline 1 & 0 & 0 & $12(38,7)$ & $12(36,4)$ & $1(3,2)$ & $1(3,0)$ & $13(41,9)$ & $13(39,4)$ \\
\hline 2 & $3(9,7)$ & $3(9,1)$ & $10(32,3)$ & $11(33,3)$ & 0 & 0 & $13(41,9)$ & $14(42,4)$ \\
\hline 3 & $1(3,2)$ & $2(6,1)$ & $3(9,7)$ & $2(6,1)$ & $1(3,2)$ & $1(3,0)$ & $5(16,1)$ & $5(15,2)$ \\
\hline 4 & 0 & 0 & 0 & $1(3,0)$ & 0 & 0 & 0 & $1(3,0)$ \\
\hline Total & $4(12,9)$ & $5(15,2)$ & $25(80,6)$ & $26(78,8)$ & $2(6,5)$ & $2(6,0)$ & $31(100,0)$ & $33(100,0)$ \\
\hline \multicolumn{9}{|c|}{ Quanto a maioria ser Membro Independente (MI) } \\
\hline$>50 \%$ de $\mathrm{MI}$ & $3(9,7)$ & $4(12,1)$ & $13(41,9)$ & $12(36,4)$ & $1(3,2)$ & $1(3,0)$ & $17(54,8)$ & $17(51,5)$ \\
\hline$<50 \%$ de $\mathrm{MI}$ & $1(3,2)$ & $1(3,0)$ & $12(38,7)$ & $14(42,4)$ & $1(3,2)$ & $1(3,0)$ & $14(45,2)$ & $16(48,5)$ \\
\hline
\end{tabular}

Fonte: Dados da pesquisa. 
possuíam, em sua maioria dois membros independentes; (2) as do Novo Mercado possuíam a maioria do comitê composto por um ou dois membros independentes e; (3) o Mercado Tradicional, representado por duas empresas, teve um comitê composto por um membro independente, e o outro por três membros independentes.

Para 2011 que: (1) quatorze das empresas observadas possuíam em seu Comitê de Auditoria dois membros independentes, representando 42,4\%; (2) treze empresas possuíam um membro independente, representado $39,4 \%$; (3) cinco empresas que possuíam três membros independentes na composição do comitê, representado $15,2 \%$ e; (4) uma empresa que possuía quatro membros independentes na composição do comitê, representando $3 \%$. O IBGC recomenda que o Comitê de Auditoria seja constituído em sua maioria por membros independentes.
Para o ano de 2010 verifica-se que $54,8 \%$ das empresas analisadas tinham seus Comitês de Auditoria formados pela maioria de membros independentes, totalizando 17 empresas que seguiram a recomendação do IBGC.

Já em 2011 constata-se, assim como em 2010, que a maior parte das empresas analisadas tinham seus Comitês de Auditoria compostos por maioria de membros independentes, sendo um total de 17 empresas, representando $51,5 \%$ das empresas observadas no ano de 2011.

Sendo também objetivo deste trabalho observar a expertise dos membros do Comitê de Auditoria a Tabela 3 destaca o que se observou junto às empresas.

Tabela 3. Quantidade de membros com expertise

\begin{tabular}{|c|c|c|c|c|c|c|c|c|}
\hline \multirow{2}{*}{$\begin{array}{c}\text { Quantidade de } \\
\text { membros }\end{array}$} & \multicolumn{2}{|c|}{ Nível 2 } & \multicolumn{2}{c|}{ Novo Mercado } & \multicolumn{2}{c|}{ Tradicional } & \multicolumn{2}{c|}{ Total } \\
\cline { 2 - 9 } & $\mathbf{2 0 1 0}$ & $\mathbf{2 0 1 1}$ & $\mathbf{2 0 1 0}$ & $\mathbf{2 0 1 1}$ & $\mathbf{2 0 1 0}$ & $\mathbf{2 0 1 1}$ & $\mathbf{2 0 1 0}$ & $\mathbf{2 0 1 1}$ \\
\hline 1 & $2(6,5)$ & $2(6,1)$ & $6(19,4)$ & $4(12,1)$ & 0 & 0 & $8(25,8)$ & $6(18,2)$ \\
\hline 2 & $1(3,2)$ & $1(3,0)$ & $6(19,4)$ & $7(21,2)$ & $1(3,2)$ & $1(3,0)$ & $8(25,8)$ & $9(27,3)$ \\
\hline 3 & $1(3,2)$ & $1(3,0)$ & $12(38,7)$ & $9(27,3)$ & $1(3,2)$ & $1(3,0)$ & $14(45,2)$ & $11(33,3)$ \\
\hline 4 & 0 & $1(3,0)$ & $1(3,2)$ & $6(18,2)$ & 0 & 0 & $1(3,2)$ & $7(21,2)$ \\
\hline
\end{tabular}

Analisando a Tabela 3, é possível verificar que 45,2\% das empresas observadas em 2010 possuíam três membros com expertise na composição do Comitê de Auditoria. Sendo que doze $(38,7 \%)$ dessas empresas pertenciam ao Novo Mercado. Percebe-se também que 25,8\% dos comitês possuía ao menos um membro com expertise.

O mesmo percentual se aplica aos comitês que possuíam dois membros com essa característica. Em 2011 a maioria dos Comitês de Auditoria era composta por três membros com expertise, totalizando onze empresas, em termos percentuais representou $33,3 \%$ do total de empresas analisadas em 2011. 27,3\% das empresas possuíam dois membros com expertise, $21,2 \%$ possuíam quatro membros e $18,2 \%$ possuíam um membro com tal característica.

\subsection{Gerenciamento de Resultados de Empresas com e sem Comitê de Auditoria}

Ao comparar o nível de gerenciamento de resultados praticados pelas empresas que possuem Comitê de Auditoria com aquelas que não possuem o comitê instalado, inicialmente procurou-se encontrar empresas que não possuem Comitê de auditoria, que fossem do mesmo nível de governança e setor daquelas que possuem o comitê instalado. Devido o fato da não existência do mesmo número de empresas sem Comitê de Auditoria que atendessem ao mesmo segmento e setor daquelas que possuem o comitê instalado, utilizou-se outros setores que correspondessem ao mesmo segmento para atender este objetivo do estudo. A seguir são analisados os níveis de gerenciamento de resultados realizados pelas empresas comparando as empresas que possuem Comitê de Auditoria com as que não possuem. Os resultados estão na Tabela 4.

Tabela 4. Descrição dos índices de GR dos anos de 2010 e 2011 por nível de GC

\begin{tabular}{|c|c|c|c|c|c|c|c|c|c|c|}
\hline \multirow{2}{*}{$\begin{array}{c}\text { NGC da } \\
\text { BM\&Fbovespa }\end{array}$} & \multicolumn{2}{|c|}{$\mathrm{N}^{0}$ empresas } & \multicolumn{2}{|c|}{ Mínimo } & \multicolumn{2}{|c|}{ Máximo } & \multicolumn{2}{|c|}{ Média } & \multicolumn{2}{|c|}{ Desvio Padrão } \\
\hline & Com & Sem & Com & Sem & Com & Sem & Com & Sem & Com & Sem \\
\hline \multicolumn{11}{|c|}{2010} \\
\hline Tradicional & 2 & 2 & $-0,1$ & $-0,12$ & $-0,01$ & $-0,11$ & $-0,06$ & $-0,12$ & 0,06 & 0,01 \\
\hline Nível 2 & 4 & 4 & $-0,17$ & $-0,20$ & $-0,03$ & 0,15 & $-0,08$ & $-0,06$ & 0,07 & 0,15 \\
\hline Novo Mercado & 25 & 25 & $-0,16$ & $-0,30$ & 0,27 & 0,40 & $-0,00$ & $-0,01$ & 0,12 & 0,15 \\
\hline Amostra total & 31 & 31 & $-0,17$ & $-0,30$ & 0,27 & 0,40 & $-0,01$ & $-0,02$ & 0,11 & 0,15 \\
\hline \multicolumn{11}{|c|}{2011} \\
\hline Tradicional & 2 & 2 & $-0,01$ & $-0,12$ & 0,04 & $-0,11$ & 0,02 & $-0,11$ & 0,04 & 0,01 \\
\hline Nível 2 & 5 & 5 & $-0,1$ & $-0,19$ & 0,08 & 0,15 & $-0,03$ & $-0,02$ & 0,07 & 0,12 \\
\hline Novo Mercado & 26 & 26 & $-0,27$ & $-0,29$ & 0,1 & 0,18 & 0,00 & $-0,02$ & 0,08 & 0,13 \\
\hline Amostra total & 33 & 33 & $-0,27$ & $-0,29$ & 0,1 & 0,18 & $\mathbf{0 , 0 0}$ & $-0,03$ & $\mathbf{0 , 0 7}$ & 0,13 \\
\hline
\end{tabular}


Verifica-se na tabela que todos os níveis de governança corporativa apresentaram gerenciamento de resultados. Observa-se que tanto em 2010 como em 2011, as empresas com Comitê de Auditoria na maioria dos ajustes feitos teve a intenção de diminuir os lucros o mesmo se observou para as empresas sem comitê. Por sua vez as empresas sem comitê apresentaram resultados mais dispersos em relação a média e acarretou em valores extremos maiores (máximo e mínimo). Empresas com o comitê de auditoria tendem a possuir gerenciamento de resultados mais padronizados e com pouca variação. No que tange os níveis de governança, um fato que deve ser destacado é a confirmação do que destaca a literatura, deque tende a ser maior em média o gerenciamento empresas sem governança, entretanto cabe destacar o confronto com a dispersão dos níveis de gerenciamento em empresas do Novo Mercado.

Realizada a análise do nível de gerenciamento nas empresas com Comitê de Auditoria versus as empresas que não possuem o Comitê de Auditoria, a seguir são apresentadas as análises dos pressupostos necessários para avaliação das variáveis que serão utilizadas para o cálculo da regressão linear múltipla, possibilitando posteriormente a realização da análise dos dados.

\subsection{Análise das Hipóteses}

Esta análise tem por objetivo explicar os dados das regressões lineares realizados para verificar a relação existente entre as variáveis que representam o comitê de auditoria e o nível de gerenciamento de resultados. Inicialmente foram verificados os modelos de regressão para ambos os anos. O método utilizado para o cálculo foi o backward (retroceder) para encontrar as variáveis independentes que no conjunto obtém um modelo significativo. Ao ser realizado o método backward utilizando os dados referentes a 2010, verificou-se que apenas três; variáveis, alavancagem, auditoria e setor, contribuíam significativamente para o modelo. Os resultados obtidos estão descrito na Tabela 5 .

Tabela 5. Resultado da regressão linear referente a 2010

\begin{tabular}{ccc}
\hline Variáveis & Coeficiente & p-value \\
(Constant) & 0,084 & 0,042 \\
Alav & $-0,009$ & 0,034 \\
Aud & 0,058 & 0,123 \\
\hline Setor & $-0,008$ & 0,166 \\
\hline $\mathrm{R}^{2}$ & & 0,249 \\
\hline Erro padrão & 0,0595 \\
\hline Sig F & 0,049 \\
\hline No de observações & 31 \\
\hline
\end{tabular}

Fonte: Dados da pesquisa.

Observa-se na Tabela 13 , por meio do $\mathrm{R}^{2}$, que a relação de explicação entre o comportamento da variável dependente pelas variáveis independentes ficou em $24,9 \%$. O modelo, como previsto pelo método backward, mostrou significância estatística ao apresentar Sig F igual a 0,049 , ou seja, está dentro do nível de significância determinado neste estudo, 5\% ou, 0,05. Verifica-se ainda que a variável alavancagem apresentou significância correspondente a 0,034, constatando-se assim que esta variável possui influência sobre a variável dependente, uma vez que está dentro da significância pré estabelecida. As variáveis auditoria e setor não possuem relação significativa a nível de $5 \%$.

Para a análise da regressão linear referente ao ano de 2011, assim como em 2010, buscou-se inicialmente, por meio do método backward encontrar as variáveis independentes que contribuíam significativamente para o modelo representado pela Equação 2, resultados estão na Tabela 6.

Tabela 6. Resultados da utilização do método backward para 2011

\begin{tabular}{c|l|l}
\hline Modelo & Sig. & Variáveis utilizadas no modelo \\
\hline 1 & 0,921 & Setor, Alav, Ind, TamCA, CV, ConcCap, Int, TamEmpln, Exp \\
\hline 2 & 0,865 & Alav, Ind, TamCA, CV, ConcCap, Int, TamEmpln, Exp \\
\hline 3 & 0,805 & Alav, Ind, TamCA, CV, ConcCap, Int, Exp \\
\hline 4 & 0,719 & Alav, Ind, TamCA, CV, ConcCap, Exp \\
\hline 5 & 0,618 & Alav, Ind, CV, ConcCap, Exp \\
\hline 6 & 0,504 & Alav, Ind, CV, ConcCap \\
\hline 7 & 0,386 & Alav, CV, ConcCap \\
\hline 8 & 0,277 & CV, ConcCap \\
\hline 9 & 0,239 & ConcCap \\
\hline Fonte: Dados da pesquisa &
\end{tabular}


Verifica-se na Tabela 6, que nenhum dos modelos apresentados demonstrou significância, uma vez que todos resultaram em Sig $>0,05$. Devido esse fato, constatou-se que em 2011 não houve relação de explicação entre o comportamento do Gerenciamento de Resultados pelas variáveis independentes.

Como o único modelo destacado como significante foi do ano de 2010, calculou-se para tanto os resultados dos pressupostos da pesquisa. O único pressuposto violado foi o de Normalidade das variáveis. Tal fato foi ocorrido que as variáveis consideradas, Aud e Setor são do tipo categórica e isso presume não normalidade. Alavancagem também não podem ser considerado como normal justamente por ser um indicador e sua concentração está mais voltada ao extremo. Os resultados são apresentados na Tabela 7.

Tabela 7. Análise dos pressupostos referidos a 2010

\begin{tabular}{c|c|c|c}
\hline Variáveis & Tolerance & VIF & KS (sig.) \\
\hline (Constant) & - & 1,001 & - \\
\hline Alav & 0,999 & 1,01 & 0,872 \\
\hline Aud & 0,99 & 1,009 & 0,872 \\
\hline Setor & 0,991 & 2,363 & 0,872 \\
\hline Durbin-Watson & \multicolumn{3}{|c|}{0,807} \\
\hline Pesarán-Pesarán & \multicolumn{2}{|c}{31} \\
\hline No de observações &
\end{tabular}

Fonte: Dados da pesquisa.

Depois de efetuada a análise dos resultados consegue-se chegar a resultados que tange a resposta das hipóteses. Assim verificou-se que nenhum dos resultados apresentados leva a confirmação das hipóteses de relação entre o comitê de auditoria, principalmente da sua composição para com o Nível de Gerenciamento de Resultados.

Desta maneira as pressuposições lançadas pelo estudo de Vlaminck e Sarens (2012), não foram confirmadas no ambiente corporativo do Brasil, ou seja, nenhuma das características do Comitê de Auditoria apresentou relação com o gerenciamento de resultados. Devido esse fato, nenhuma das hipóteses formuladas foi aceita. Consequentemente, o mesmo ocorreu com as subhipóteses analisadas, uma vez que, para realizar a análise a qual se referiam essas sub-hipóteses, fazia-se necessário que as variáveis independentes tivessem apresentado alguma relação, positiva ou negativa, com a variável dependente. Assim se verificou que apenas em 2010, uma variável independente, sendo ela uma variável de controle alavancagem, apresentou relação significativa com o gerenciamento de resultados.

\section{CONCLUSÃO}

O estudo realizado teve como objetivo verificar se as características do Comitê de Auditoria que refletem no gerenciamento de resultados das empresas brasileiras listadas na BM\&FBovespa. A metodologia utilizada foi a pesquisa descritiva, com aplicação de procedimento documental, utilizando-se das informações publicadas nos formulários de referência disponibilizados pelas empresas no sítio da BM\&FBovespa, bem como por informações complementares constadas nos sítios das próprias empresas. Quanto à abordagem do problema, o estudo foi caracterizado como quantitativo, empregandose a técnica de regressão linear múltipla.
Do total de empresas listadas na BM\&FBovespa, excluídas as financeiras, verificou-se que 61 empresas possuem Comitê de Auditoria instituído, sendo um total 41 empresas do Novo Mercado, 6 empresas do Nível 2, 5 empresas do Nível 1 e 9 empresas do Mercado Tradicional. Das 61 empresas que possuem Comitê de Auditoria, verificou-se que, 31 empresas possuíam em 2010 todas as características relacionadas ao tamanho do comitê, independência e expertise dos membros. Em 2011 o total de empresas com tais características aumentou, passando para 33 empresas. Quanto a característica expertise, constatou-se que em 2010, 14 empresas $(45,2 \%)$ possuíam pelo menos um, destes a distribuição foi de 3 membros com expertise, 8 empresas $(25,8 \%)$ que possuíam 2 membros, bem como 8 empresas $(25,8 \%)$ que possuíam 1 membro com tal característica. Apenas uma empresa, representando $3,2 \%$ do total da amostra, apresentou em seu Comitê de Auditoria 4 membros com expertise. Em 2011 a quantidade de membros com tal característica diversificou-se, sendo que 11 empresas $(33,3 \%)$ apresentaram 3 membros com expertise, 9 empresas $(27,3 \%)$ com dois membros, 7 empresas $(21,2 \%)$ com 4 membros e 6 empresas $(18,2 \%)$ com apenas um membro com expertise.

Constatou-se, em relação à característica independência, que no ano 2010, os Comitês de Auditoria eram, em sua maioria, constituídos por 1 ou 2 membros independentes, sendo um total de 13 empresas com um membro independente, bem como 13 empresas com 2 membros independentes. Em 2011, a maioria das empresas possuíam em seu Comitê de Auditoria 2 membros independentes, representando $42,2 \%$ da amostra total do respectivo ano. No mesmo ano, também teve uma significativa quantidade de empresas que possuíam em seu comitê apenas um membro independente, um total de 13 empresas, representando $39,4 \%$.

No que tange a relação do Gerenciamento de Resultados e as características do comitê de auditoria, no ano 2010 
constatou-se que apenas três variáveis, alavancagem, auditoria e setor contribuíam significativamente para o modelo inicial. Averiguou-se que apenas a variável alavancagem apresentou influência sobre a variável dependente. Já o ano 2011, na realização do método backward, não apresentou nenhum novo modelo, ou seja, demonstrou que nenhuma das variáveis independentes apresenta relação com a variável dependente denominada gerenciamento de resultados.

Em resposta ao objetivo geral, verificar se as características do Comitê de Auditoria refletem no gerenciamento de resultados das empresas brasileiras listadas na BM\&FBovespa, bem como resposta da questão problema do estudo, se pode verificar que nenhuma das características do Comitê de Auditoria estudadas apresentaram influência sobre o gerenciamento de resultados. Apesar de estudos anteriores apresentarem a existência dessa relação, para a amostra utilizada nesse estudo esta relação não ocorreu. Diante disso nenhuma das hipóteses formuladas foi aceita.

\section{REFERÊNCIAS}

ABBOTT, L. J., PARK, Y., PARKER, S. The effects of audit committee activity and independence on corporate fraud. Managerial Finance. v. 26, n. 11, p. 55-67. 2000.

ALMEIDA, J. E. F. Qualidade da informação contábil em ambientes competitivos. 2010. 174 f. Tese (Doutorado em Ciências Contábeis) Programa de Pós-Graduação em Controladoria e Contabilidade do Departamento de Contabilidade e Atuária da Faculdade de Economia, Administração e Contabilidade da Universidade de São Paulo, 2010.

ANDRADE, M. M. Introdução à metodologia do trabalho científico. 10 ed. São Paulo: Atlas, 2010.

BEASLEY, M. S., SALTERIO, S. E. The relationship between board characteristics and voluntary improvements in audit committee composition and experience. Contemporary Accounting Research, Toronto, v. 18, n. 4, p. 539-570, inverno. 2001.

BÉDARD, J., CHTOUROU, S., COURTEAU, L. The effect of audit committee expertise, independence, and activity on aggressive earnings management, auditing. Journal of Practice \& Theory, v. 23, no. 2, p. 13-35. 2004.

BM\&FBOVESPA. Empresas listadas. Disponível em: $\quad<$ http://www.bmfbovespa.com.br/ciaslistadas/empresas-listadas/BuscaEmpresaListada. aspx?idioma $=$ pt-br>.

BRASIL. Lei 6.404, de 15 de dezembro de 1976. Dispõem sobre as sociedades por ações.

BRONSON, S. N., CARCELLO, J. V., HOLLINGSWORTH, C. W., NEAL, T. L. Are fully independent audit committees really necessary? Journal of Accounting and Public Policy. v. 28, v.
4, p. 265-280. 2009.

CARCELLO, J., HOLLINGSWORTH, C., KLEIN, A., NEAL, T.. Audit committee financial expertise, competing corporate governance mechanisms, and earnings management. Accounting Horizons, v. 20, n. 4, p. 351-37. 2006.

CARDOSO, R. L. Regulação econômica e escolha de práticas contábeis: evidências no mercado de saúde suplementar brasileiro. 2005. 163 f. Tese (Doutorado em Ciências Contábeis) Programa de Pós-Graduação em Controladoria e Contabilidade do Departamento de Contabilidade e Atuária da Faculdade de Economia, Administração e Contabilidade da Universidade de São Paulo, 2005.

COHEN, J., KRISHNAMOORTHY, G., WRIGHT, A. The corporate

governance mosaic and financial reporting quality. Journal of Accounting Literature. v. 23, p. 87152. 2004.

CUNHA, P. R. Proposta sistematizada de características e ações dos agentes internos da governança corporativa que possa contribuir à qualidade das demonstrações contábeis. 2011. 244 f. Tese (Doutorado em Ciências Contábeis) - PPGCC - Universidade Regional de Blumenau, Blumenau, 2011.

CUNHA, J. V. A.; COELHO, A. C. (2007). Regressão linear múltipla. In L. J. Corrar, E. Paulo, \& J. M., Dias, Filho (Coords.), Análise multivariada: para os cursos de administração, ciências contábeis e economia (pp. 131-231). São Paulo: Atlas.

DEFOND, M., HANN, R., HU, X. Does the market value financial expertise on audit committees of boards of directors? Journal of Accounting Research, v. 43, n. 2, p. 153-193. 2005.

FUJI, A. H.. Gerenciamento de resultados contábeis no âmbito das instituições financeiras atuantes no Brasil. 2004. 132 f. Dissertação (Mestrado em Ciências Contábeis) - Programa de Pós-Graduação em Controladoria e Contabilidade do Departamento de Contabilidade e Atuária da Faculdade de Economia, Administração e Contabilidade da Universidade de São Paulo, 2004.

FURUTA, F.. A relação das características das empresas com a adoção do comitê de auditoria x conselho fiscal adaptado. 2010. 189 f. Tese (Doutorado em Ciências Contábeis) - PPGCC FEA, Universidade de São Paulo, São Paulo, 2010.

GIL, A. C. Métodos e técnicas de pesquisa social. 5 ed. São Paulo: Atlas, 1999.

GOULART, A. M. C. Gerenciamento de resultados contábeis em instituições financeiras no Brasil. 2007. 219 f. Tese (Doutorado em Ciências Contábeis) Programa de Pós-Graduação em Controladoria e Contabilidade do Departamento de Contabilidade e Atuária da Faculdade de Economia, Administração e Contabilidade da Universidade de São Paulo, São Paulo, 2007.

HEALY, P. M,WAHLEN, J. M.. A review of the earnings management literature and its implications for standard setting. Accounting Horizons, Sarasota, 
v. 13, n. 4 , p. 365,19 pgs. 1999.

INSTITUTO BRASILEIRO DE GOVERNANÇA CORPORATIVA - IBGC. Código das melhores práticas de governança corporativa, 4. ed., 2009. São Paulo, 2009a.

INSTITUTO BRASILEIRO DE GOVERNANÇA CORPORATIVA. Guia de orientações para melhores práticas de comitês de auditoria, 7. ed., 2009. São Paulo, 2009b.

JIRAPORN, P., MILLER, G. A., YOON, S. S., KIM, Y. S. Is iarnings management opportunistic or beneficial? An Agency Theory Perspective. International Review of Financial Analysis. v. 17, p. 622-634, 2008.

KENT, P., ROUTLEDGEA, J., STEWAR, J. Innate and discretionary accruals quality and corporate governance. Accounting and Finance, v. 50, p. 171-195. 2010.

KLANN, R. C. Gerenciamento de resultados: análise comparativa de empresas brasileiras e inglesas antes e após a adoção das IFRS. 2011. 372 f. Tese (Doutorado em Ciências Contábeis e Administração) - PPGCC, Universidade Regional de Blumenau, Blumenau, 2011.

KLEIN, A. Audit committee, board of director characteristics, and earnings management. Journal of Accounting and Economics, New York, v. 33, n. 3, p. 375-400, fevereiro 2002.

KRISHNAN, J. Audit committee quality and internal control: an empirical analysis. The accounting review, v. 80, n. 2, p. 649-675, abril 2005

Lopes, A. B. Normas internacionais de contabilidade. In: José Francisco Ribeiro Filho, Jorge Lopes e Marcleide Pederneiras. (Org.). Estudando teoria da contabilidade. 1 ed. São Paulo: Atlas, 2009, v. , p. 283-292.

MARTINEZ, A. L. "Gerenciamento" dos resultados contábeis: estudo empírico nas companhias abertas brasileiras. 2001. 167 f. Tese (Doutorado em Ciências Contábeis) Programa de Pós-Graduação em Controladoria e Contabilidade do Departamento de Contabilidade e Atuária da Faculdade de Economia, Administração e Contabilidade da Universidade de São Paulo, 2001.

MARTINEZ, A. L. Detectando earnings management no Brasil: estimando os accruals discricionários. Revista Contabilidade e Finanças, São Paulo, v. 19, n. 46, p. 7-17, janeiro/abril, 2008.

MCDANIEL, L., MARTIN, R. D., MAINES, L. A., PEECHER, M. E. Evaluating financial reporting quality: the effects of financial expertise vs financial literancy. The Accounting Review. v. 77 Suplement. p. 139-167, 2002.

PAULO, E. Manipulação das informações contábeis: uma análise teórica e empírica sobre os modelos operacionais de detecção de gerenciamento de resultados. Tese (Doutorado em Ciências Contábeis) Programa de Pós-Graduação em Controladoria e Contabilidade do Departamento de Contabilidade e Atuária da Faculdade de Economia, Administração e Contabilidade da Universidade de São Paulo,
2007.

RICHARDSON, R. J. Pesquisa social: métodos e técnicas. 3 ed. São Paulo: Atlas, 2012.

SANTOS, A., PAULO, E. Diferimento das perdas cambiais como instrumento de gerenciamento de resultados. Brazilian Business Review, vol. 3, núm. 1, p. 15-31, jan/jun, 2006.

SCHIPPER, K. Commentary: earnings management. Accounting Horizons. v. 3, p. 91-102, dez. 1989.

SIFFERT, N. Governança corporativa: padrões internacionais e evidências empíricas no Brasil nos anos 90. Revista do BNDES. Rio de Janeiro. v.5, n.9, p. 123-46, junho de 1998.

SILVEIRA, A. D. M. Governança corporativa, desempenho e valor da empresa no Brasil. 2002. 165 f. Dissertação (Mestrado em Administração) FEA Universidade de São Paulo, São Paulo, 2002.

SOUZA, P. C. S. S. Práticas do comitê de auditoria: evidências de empresas brasileiras. 2010. $133 \mathrm{f}$. Dissertação (Mestrado em Ciências Contábeis) Programa de Pós-Graduação em Controladoria e Contabilidade do Departamento de Contabilidade e Atuária da Faculdade de Economia, Administração e Contabilidade da Universidade de São Paulo, São Paulo, 2010.

TRAPP, A. C. G. A relação do conselho fiscal como componente de controle no gerenciamento de resultados contábeis. 2009. 141 f. Tese (Doutorado em Ciências Contábeis) - PPGCC - FEA Universidade de São Paulo, São Paulo, 2009.

TURLEY, S., ZAMAN, M. The corporate governance effects of audit committees. Journal of Management and Governance, v. 8, p. 305-332. 2004.

VIANA, E. A governança corporativa no setor público municipal - um estudo sobre a eficácia da implementação dos princípios de governança nos resultados fiscais. 2009. 121 f. Dissertação (Mestrado em Ciências) - PPGCC - FEA Universidade de São Paulo, Ribeirão Preto, 2010.

VLAMINCK, N., SARENS, G. The relationship between audit committee characteristics and financial statement quality: evidence from Belgium. In: European Accounting Association, Annual Congress, 35, 2012, Ljubljana.

WANG, D. Founding family ownership and earnings quality. Journal of Accouting Research, v. 44, n. 3, June 2006.

YANG, J., KRISHNAN, J. Audit committees and quarterly earnings management. International Journal of Auditing, v. 9, n. 3, p. 201-219. 2005. 